\title{
Need-Fulfillment and Self-Expansion as Predictors of Marital Commitment Among Students
}

\author{
Gholamreza Rajabi, ${ }^{1,}$ Mehravar Momeni Javid, ${ }^{2}$ and Arash Jelodari ${ }^{3}$ \\ ${ }^{1}$ Professor of Counseling, Shahid Chamran University of Ahvaz, Ahvaz, Iran \\ ${ }^{2}$ Ph.D. in Counseling, Shahid Chamran University of Ahvaz, Ahvaz, Iran \\ ${ }^{3}$ Graduate Student of Counseling, Shahid Chamran University of Ahvaz, Ahvaz, Iran \\ "Corresponding author: Gholamreza Rajabi, Department of Counseling, Faculty of Education and Psychology, Shahid Chamran University, Ahvaz, Iran. E-mail: \\ rajabireza@scu.ac.ir
}

Received 2016 February 11; Revised 2017 January 16; Accepted 2017 February 15.

\begin{abstract}
Background: A fundamental assumption for most romantic relationships is that of exclusivity, the belief that both partners are emotionally and sexually committed to each other solely.

Objectives: This study attempted to examine the predictors of marital commitment by need-fulfillment and self-expansion among married students.

Methods: A convenience-voluntary sample of 194 married-students took part in the study. They completed need-fulfillment measure, self-expansion questionnaire, and marital commitment inventory. The data were analyzed using Pearson correlation coefficient and regression analysis by SPSS-PC (v.21).

Results: Pearson correlation coefficients showed significant correlations between all the study variables. Multiple regression analysis revealed that need-fulfillment and self-expansion were predictors of marital commitment.

Conclusions: Loyalty to spouse and family values, and the actualization of one's potential gifts will lead to marital commitment.
\end{abstract}

Keywords: Need-Fulfillment, Self-Expansion, Marital Commitment, Married Students

\section{Background}

A fundamental assumption for most romantic relationships is that of exclusivity, the belief that both partners are emotionally and sexually committed to each other solely (1). Although the husband and the wife have the feelings of constant commitment in the early days of marriage, sometimes it is not a permanent commitment (2). Snyder, Baucom, and Gordon have reported the marital infidelity as the most important cause of divorce (3). According to McCarthy, marital commitment refers to staying loyal to the family and its members during sadness and happiness, health and sickness, which is defined based on both emotion/affection and intention/goal (4). Responsibility, loyalty, amnesty, promise- and word-keeping, trust, love, and interest are the features of commitment. Also, the lack of commitment, courtship, and sexual promiscuity are associated with decreased sexual satisfaction, depression, suspicion, increased possibility of separation, and distrust $(5,6)$.

Satisfying the needs is a fundamental rule in improving marital relationships. According to the deficit theory, when a marriage, in some cases, faces deficits such as low satisfaction of the relationship, or fails to satisfy the sexual needs, etc., it would lead to non-commitment and abjuration. According to research, extra-marital relation- ships have the necessary potential for achieving positive outcomes including personal growth and self-discovery, which one's current relationship fails to provide. In this context, "need fulfillment" and "self-expansion" theories are based on "deficit theory" (7).

Self-expansion is another incentive which is important in marital relationships. It is considered as an incentive process which its ultimate goal is to realize one's potentials. One of the strategies toward achieving the goal is inclusion of the other in self (8). Gaining new insights, skills, abilities, and policies will lead to the increased selfefficacy and self-promotion. One of the pathways for personal growth and actualization is sharing and companionship with the spouse in achieving actions and experiences (9). When novelty of a relationship reduces, couples' participation in new activities is one of the pathways to experience self-expansion. Engaging in novel and creative activities will lead to self-growth and self-expansion which has negative and positive relationships with tedium and boredom feelings and quality of life, respectively (10). The process happens in a way that the individual accepts the characteristics of the other as his/her own characteristics (11). Thus, the distinction between self and spouse would fade away. Self-expansion is positively related to relationship satisfaction. If the marital relationship does not provide 
the possibility of personal growth and actualization, the individual will be encouraged to meet the need from illegal and unethical resources. Studies indicated that the capacity and ability of marital relationship to establish selfexpansion are related to commitment to the spouse (7).

VanderDrift, Lewandowski, and Agnew indicated that the couples who have less potential of self-expansion in their relationship show more tendency to other choices, and the failure caused by motivational bias (depreciation) and perceptual bias (lack of attention to attractive options) has an impact on the tendency and attention to other options (12). Mitchell, Bartholomew, and Cobb showed that the higher was the partners' need-fulfillment in the relationship, the higher was their commitment to their marriage (13). Also, Fivecoat, Tomlinson, Aron, and Caprariello found that the relationship satisfaction increased more significantly in those who received active (instead passive) support for self-expansion (14).

In Iranian society, marital commitment has a high ethical and religious importance. If there is a gap in trust and feelings of safety between couples, dynamism and vitality of life will be lost and it leads to the feelings of injury in one couple or both couples and the focus of family would be threatened. Nevertheless, little research has been conducted in the context of marital commitment relationship with other variables. If couples do not pay attention to each other's needs and expectations and do not prepare the backgrounds of self-actualization and personal growth and they are not aware of predisposing factors to the occurrence of such events, then the likelihood of noncommitment and disloyalty will increase.

\section{Objectives}

This study aimed to investigate need fulfillment and self-expansion as predictors of marital commitment among a sample of married students.

\section{Methods}

The current study is of correlation-regression type. The study sample consisted of 194 married students, recruited from different universities including Tehran University $(n=19)$, Shahid Beheshti University $(n=56)$, Allameh Tabatabai University $(\mathrm{n}=44)$, and Alzahra University $(n=75)$ who took part voluntarily. The selection of the students was in accordance with the following inclusion criteria: being married at least for 1 year, having no marital problems, having no mood and affective disorders, and being willing to participant in the study. The students not having these criteria and those who were not willing to participate were excluded from the research. Then, the objectives of the research were clarified to the participants and after obtaining their oral informed consent, the research procedure began. To collect data, an approval was obtained from education departments of the mentioned universities. Objectives and application of the research on married students were explained to the participants individually. Also, the participants were told that they can take part in the research voluntarily with full consent and everyone who is reluctant to participate can quit the research. Information on how to respond to each questionnaire was conveyed to the participants and they were told that their personal information and responds will remain confidential and the data will be analyzed collectively. In order to meet ethical considerations, full informed consent was obtained from the participants, and the questionnaires were filled anonymously to ensure confidentiality of responses. The questionnaires were verified to ensure that all the questions were answered completely.

\subsection{Measures}

\subsubsection{Need Fulfillment Measure (NFM)}

This questionnaire was developed by Lee and Agnew in 2001 and includes 5 items, one for each need in marital relationships (intimacy, companionship, sexual relationship, safety, and emotional needs) (15). The items of the scale are scored on a 6-point Likert scale ranging from 0 (not satisfied) to 6 (fully satisfied by spouse), where a higher score indicates more need fulfillment. The items of the NFM were separately translated into Persian by the authors. The translated versions were then compared with the original form by a psychologist, fluent in English, and the words were modified and confirmed as adequately representing the original items. The primary Persian version was again translated into English and compared with the original form, which showed high similarity between the two forms. Lee and Agnew showed Cronbach's $\alpha$ coefficient of 0.92 (15). In the current study, the Cronbach's $\alpha$ coefficient for NFM was obtained as 0.91 .

\subsubsection{Self-Expansion Questionnaire (SEQ)}

The questionnaire of self-expansion was developed by Lewandowski and Aron to assess the extent of expansion and growth of self as a result of novelty, creativity, and challenges of the marital relationship (16). The SEQ contains 14 items scored on a 7-point Likert scale, ranging from $1=$ Not much to $7=$ Very much. The total score of the SEQ can range from 14 to 98, with higher scores indicating higher self-expansion. The items of SEQ were separately translated into Persian by the authors. The translated versions were then compared with the original text by a psychologist, 
fluent in English, and the words were modified and confirmed as adequately representing the original items. The primary Persian version was again translated into English and compared with the original form, which showed high similarity between the two forms. Lewandowski and Aron, and Lewandowski and Ackerman obtained Cronbach's $\alpha$ reliability coefficient of the SEQ as 0.87 and 0.89 , respectively $(7,16)$. In this study, Cronbach's alpha coefficient of the SEQ was calculated as 0.92 .

\subsubsection{Dimensions of Commitment Inventory (DCI)}

The DCI was developed by Adams and Jones to measure 3 subscales (commitment to spouse, commitment to marriage, and mandatory commitment) (cited in 18). The 44 items of this inventory are scored on a 5-point Likert scale ( 1 = completely disagree to $5=$ completely agree). The total score can range from 44 to 220. A higher score indicates higher marital commitment. Shahsiah, Bahrami, and Mohebi confirmed the content validity and face validity of the instrument by 5 counseling professors of the faculty of education and psychology at Isfahan University (17). They and Asgari, Pasha, and Azar Kish obtained Cronbach's $\alpha$ reliability coefficients of 0.85 and 0.74 , respectively $(17,18)$. In this study, Cronbach's alpha reliability coefficient of the DCI was calculated as 0.71 .

\subsection{Procedure}

Before conducting the research, students of every educational department were briefed about the aim of the research and instructions on how to complete the instruments. The Persian versions of the questionnaires were administered individually in appropriate rooms. The participants were initially assured that their responses are confidential and the data will be analyzed as groups. However, some students were omitted from the research because they were not cooperating in completing the questionnaires.

\subsection{Data Analysis}

The SPSS-21 was used for data analysis. The following data analysis methods were applied: (1) descriptive statistics for summarizing the data, (2) Pearson correlation coefficient for investigating the relationship between the study variables, (3) Multiple regression analysis for estimating the predictors of marital commitment, i.e. need fulfillment and self-expansion and, (4) Cronbach's alpha for examining the internal consistency of the scales.

\section{Results}

As shown in Table 1, the mean age of participants was $28.90(S D=8.08)$ in the range of 19 to 58 years; the mean age at marriage was 22.51 ( $\mathrm{SD}=3.59)$ and the mean duration of marriage was $6.31(\mathrm{SD}=7.91)$.

Table 1. Demographical Characteristics

\begin{tabular}{lcc}
\hline Participants age & $\mathbf{x}^{-}=\mathbf{2 8 . 9}$ & SD $=\mathbf{8 . 0 8}$ \\
\hline Mean age at marriage & 22.51 & 3.59 \\
Mean $_{\text {duration of marriage }}$ & 6.31 & 7.91 \\
\hline
\end{tabular}

Table 2 shows the descriptive statistics and the correlations between the variables.

Table 2. Descriptive Statistics and Pearson Correlation Between the Variables in Sample Students $(\mathrm{N}=194)$

\begin{tabular}{lccc}
\hline Variable & Mean & SD & marital commitment \\
\hline Need fulfillment & 76.98 & 12.55 & $0.26^{\mathrm{a}}$ \\
Self-expansion & 74.04 & 14.56 & $0.30^{\mathrm{a}}$ \\
\hline Marital commitment & 153.12 & 22.11 & - \\
\hline
\end{tabular}

${ }^{\mathrm{a} P} \leq 0.001$

As shown in Table 2, all the correlations were statistically significant and positive.

The co-linearity statistics including tolerance coefficient $(\mathrm{T}=0.83)$ and variance inflation factor $(\mathrm{VIF}=1.19)$ showed that the correlation of one predicting variable with another predicting variable is low. In other words, the values show that two of the predicting variables are appropriate.

The linear combination of predictor variables, i.e. need fulfillment and self-expansion, to explain marital commitment variable showed a significant relationship, i.e., the two variables play the role of important predictors in explaining the variance of marital commitment variable ( $R$ $=0.34)$. Altogether, 0.12 of the variance in marital commitment is explained by the two predictor variables. Regression weights $(\beta)$ revealed that self-expansion with $\beta=0.24$ plays a more important role than need fulfillment $(\beta=0.17)$ in explaining marital commitment. Marital commitment prediction formula based on the predictor variables is as follows:

$y=103.74+0.24$ (self-expansion) +0.17 (need fulfillment)

\section{Discussion}

This study was conducted to examine the predicting role of need fulfillment and self-expansion in marital commitment among married university students in Tehran. 
The findings indicated that need fulfillment and capacity/actualization of self are related to loyalty to spouse and family. Of course, the self-expansion variable as an incentive component had more contribution to staying loyal to family in comparison with need fulfillment variable (see Tables 2 and 3). The wife and the husband are legally committed to each other in terms of emotional and sexual issues. In the early days of marriage, this commitment is stronger among partners (2). Non-commitment of couples, however, is the main reason for divorce. The need fulfillment can be considered as an indicator due to its impact on determining the couples' marital satisfaction (15). Drigotas and Rusbult believe that in addition to one's own emotions, the spouse's emotions and feelings should be considered in marital relationships (19). It seems that all of the needs are not typically fulfilled appropriately in marital relationships, leading to problems such as non-commitment to the spouse in couples' relationships. This means that if a relationship is unable to fulfill specific needs, one will likely seek other resources to fulfill them.

Table 3. Need Fulfillment and Self-Expansion as Predictors of Marital Commitment

\begin{tabular}{lccc}
\hline Variable & B & $\beta$ & T \\
\hline Intercept & 103.74 & - & $10.04^{\mathrm{a}}$ \\
Self-expansion & 0.36 & 0.24 & $3.18^{\mathrm{a}}$ \\
Need fulfillment & 0.29 & 0.17 & $2.22^{\mathrm{a}}$ \\
\hline
\end{tabular}

${ }^{\mathrm{a}} \mathrm{F}$-ratio $=12.49, \mathrm{P}<0.001$.

Moreover, self-expansion and/or personal growth and actualization are incentive processes with ultimate goal of realization of one's potentials and the "who I am" need. If a marriage does not provide the possibility of personal growth and actualization, both partners may seek to meet their needs from illegal and unethical resources. However, if a person feels, for example, that he/she cannot establish close, intimate relationships with his/her spouse, he/she will probably be more prone to non-commitment to the spouse. On the other hand, the invest model argues that commitment is formed based on the extent of one's attachment feelings toward the spouse and the interest in keeping the relationship with him/her and as a result, the interdependency of couples would form. If couples meet each other's expectations and the positive aspects of their relationship are more than negative ones, they will feel a greater sense of satisfaction and therefore, they will also have greater commitment. Also, when couples invest more on sources such as opportunities of being together, their emotions and feelings, their common character, and the likelihood of commitment and loyalty to each other would increase (20). The research of Lewandowski and Ackerman confirms the findings of the current research (7). In this case, if a relationship can lead to the fulfillment of needs, it would become viable.

\subsection{Conclusion}

Marital commitment means staying loyal to family and its members in various life crises such as sadness and happiness based on the feelings and emotions. With being loyal to the family and its members, people can resolve the problems and crises they face with. This is not feasible unless people's needs are met in family and there are opportunities for growth and development for members. Love, promise-keeping, intimacy, remission, responsibility, and reliance are the signs of a committed family which could affect couples' marital satisfaction. In marital relationships, it is possible that all of the needs are not met which in turn, can cause problems in their relationships such as lack of commitment to the spouse. Also, there should be infrastructures for actualization of couples' potentials through companionship and collaboration with spouse in different areas or in other words, inclusion of the other in self and establishing close, intimate relationships. Otherwise, if there is not any chance for couples' self-actualization and personal growth, the needs may be met in illegal and unethical ways. If one could not establish these intimate and close relationships with his/her partner, his/her commitment to the marital life might decrease. In summary, secure and reciprocal depended couples have positive thinking so that even when face with marital problems, their lives go on. This is because of positive investment in life which can bring about more satisfaction in their lives, as well.

Of the limitations of the research is that the population was restricted to the sample of university students and the results, therefore, should be generalized to other populations with caution. The researchers recommend to use non-student populations with limited age range in future studies. Also, it is suggested to enter the self-expansion variable in the equation as a moderator variable so as to its role would be examined more precisely.

\section{Acknowledgments}

Hereby, we appreciate all the students who took part in the study with patience and tolerance and spent their precious time for completing the questionnaires. Also, the educational departments of different Universities in Tehran are greatly acknowledged for paving the way for ratification and implementation of this study. 


\section{Footnote}

Conflict of Interests: The authors declare that there is no conflict of interest in this study.

\section{References}

1. Treas J, Giesen D. Sexual infidelity among married and cohabiting americans. J Marriage Fam. 2000;62(1):48-60. doi: 10.1111/j.17413737.2000.00048.x.

2. Sprecher S, Wenzel A, Harvey J. Handbook of relationship initiation. New York: Taylor \& Francis Group; 2008.

3. Snyder DK, Baucom DH, Gordon KC. An integrative approach to treating infidelity. Fam J. 2008;16(4):300-7. doi:10.1177/1066480708323200.

4. McCarthy BW. Marital style and its effects on sexual desire and functioning.JFam Psychol Ther. 1999;10(3):1-12. doi:10.1300/J085v10n03_01.

5. Masters A. Marriage, commitment and divorce in a matching model with differential aging. Rev Econ Dynam. 2008;11(3):614-28. doi: 10.1016/j.red.2007.08.005.

6. Tilghman-Osborne C, Cole DA, Felton JW, Ciesla JA. Relation of guilt, shame, behavioral and characterological self-blame to depressive symptoms in adolescents over time. J Soc Clin Psychol. 2008;27(8):80942. doi: 10.1521/jscp.2008.27.8.809.

7. Lewandowski GW, Ackerman RA. Something's missing: Need fulfillment and self-expansion as predictors of susceptibility to infidelity. $J$ Soc Psychol. 2006;146(4):389-403. doi: 10.3200/socp.146.4.389-403.

8. Harris SG. Self-expansion in adults aged 50 and older: The role of volunteering. 2011.

9. Aron A, Norman CC, Aron EN, Lewandowski GWJR. In: Marital interaction. P. Noller J. Feeney, editor. New York:: Cambridge University Press; 2003. pp. 177-96.Shared participation in self-expanding activities: Positive effects on experienced marital quality.
10. Acevedo BP, Aron A. Does a long-term relationship kill romantic love?. Rev Gen Psychol. 2009;13(1):59-65. doi: 10.1037/a0014226.

11. Aron A, Aron EN, Tudor M, Nelson G. Close relationships as including other in the self.JPers Soc Psychol. 1991;60(2):241-53. doi:10.1037/00223514.60.2.241.

12. VanderDrift LE, Lewandowski GW, Agnew CR. Reduced self-expansion in current romance and interest in relationship alternatives.J Soc Pers Relat. 2011;28(3):356-73. doi: 10.1177/0265407510382321.

13. Mitchell ME, Bartholomew K, Cobb RJ. Need fulfillment in polyamorous relationships. J Sex Res. 2013;51(3):329-39. doi: 10.1080/00224499.2012.742998.

14. Fivecoat HC, Tomlinson JM, Aron A, Caprariello PA. Partner support for individual self-expansion opportunities. J Soc Pers Relat. 2015;32(3):368-85. doi: 10.1177/0265407514533767.

15. Le B, Agnew CR. Need fulfillment and emotional experience in interdependent romantic relationships.J Soc Pers Relat. 2001;18(3):423-40. doi: $10.1177 / 0265407501183007$.

16. Lewandowski GWJR, Aron A. The Self-expansion Scale: Construction and validation. Paper presented at the third annual meeting of the society of personality and social psychology 2002 February. Savannah, GA. .

17. Shahsiah M, Bahrami F, Mohebi S. On the relationship between sexual satisfaction and marital commitment among couples in Shahreza city, central part of Iran [In Persian]. J Fundam Ment Health. 2009;11(43):233-8.

18. Asgari P, Pasha G, Azar Kish M. Comparison of marital commitment, sexual satisfaction, and life satisfaction of housewives and working women [In Persian]. Iran J Psychiat Clin Psychol. 2011;6(21):53-60.

19. Drigotas SM, Rusbult CE. Should I stay or should I go? A dependence model of breakups. J Pers Soc Psychol. 1992;62(1):62-87. doi: 10.1037/0022-3514.62.1.62.

20. Paniccia L. Self-expansion and couple possessions: The representation of the self and other in valued possessions. 2011. 